

\title{
Editorial
}

\section{When should an article be retracted?}

\author{
Malcolm Boyle PhD'
}

\author{
Affiliation: \\ 'Monash University, Victoria
}

On rare occasions an issue with the integrity of a scientific article is identified after publication or raised by reviewers during the review process. The integrity issue identified after the article is published is normally dealt with under an article retraction process. A retraction article is intended to ensure integrity of the published scientific literature in alerting the readership to erroneous results, duplicate publications, plagiarism, and issues of unethical research conduct.

There are three main levels within the Committee on Publication Ethics (COPE) Retraction Guidelines; retraction of a publication, expression of concern, and correction (1). The COPE Retraction Guidelines suggest that editors consider retraction of a publication if there is clear evidence of misconduct, be it intentional or an honest mistake, a case of a redundant publication, plagiarism or unethical research (1).

An expression of concern may be issued by the editor if they consider there is inconclusive evidence of misconduct, the results are unreliable but the author's institution will not investigate the issue, an investigation into misconduct would or has not been conducted fairly, or the results of an investigation are still pending (1).

A correction may be considered if the editor believes a small section of the article is misleading due to an honest mistake and the author list is incorrect due to omission or addition of an author.

The issue of retracting a published article by a journal editor is not taken lightly with most journals following the COPE guidelines for retraction of an article (1). The Australasian Journal of Paramedicine (AJP) uses the COPE guidelines to manage various aspects of the manuscript handling and publication process.

It is important to note also that the views expressed by the authors of articles published in the Australasian Journal of Paramedicine are not necessarily those of the publisher (Paramedics Australasia) or the editorial staff and should not be quoted or considered as such.

Dr Mal Boyle

Editor

Australasian Journal of Paramedicine

\section{Reference}

1. Committee on Publication Ethics. COPE guidelines for retracting articles. Committee on Publication Ethics; 2009. Available at: www.publicationethics.org/files/retraction guidelines.pdf [Last Updated: September 2009; Accessed 6 January 2015]. 